\title{
Heterotopic pregnancy: a case report
}

\author{
Amit Gupta ${ }^{1 *}$, Aanchal Gupta ${ }^{1}$, Bharti Gupta ${ }^{2}$, Neelam Mahajan', \\ Anju Vij ${ }^{1}$, Abhinav Chadha ${ }^{1}$
}

\author{
${ }^{1}$ Department of Obstetrics and Gynecology, ${ }^{2}$ Department of Anesthesiology, Dr. RPGMC Tanda, Kangra, Himachal \\ Pradesh, India
}

Received: 08 February 2017

Revised: 13 March 2017

Accepted: 23 March 2017

\section{*Correspondence:}

Dr. Amit Gupta,

E-mail: dramit203@yahoo.com

Copyright: $(\odot$ the author(s), publisher and licensee Medip Academy. This is an open-access article distributed under the terms of the Creative Commons Attribution Non-Commercial License, which permits unrestricted non-commercial use, distribution, and reproduction in any medium, provided the original work is properly cited.

\begin{abstract}
Heterotopic pregnancy is defined as the coexistence of intrauterine and extrauterine gestation. The incidence is low and estimated to be 1 in 30,000 of spontaneous pregnancies though it is becoming commoner with assisted reproductive technique. It can be a life-threatening condition and can be easily missed with the diagnosis being overlooked. We present a rare case of spontaneous heterotopic pregnancy with live intrauterine gestation and ruptured left adnexal gestation.
\end{abstract}

Keywords: Heterotopic pregnancy, Ruptured ectopic, Spontaneous

\section{INTRODUCTION}

Heterotopic pregnancy is defined as the coexistence of intrauterine and extrauterine gestation. ${ }^{1,2}$ It is a rare occurrence. It was first reported in 1708 by Duverney as an incidental finding of intrauterine pregnancy while doing an autopsy of a patient who died due to ruptured ectopic pregnancy. The incidence in the general population is estimated to be 1 in 30,000 , while a rate as high as 1 in 8,000 has been reported. ${ }^{3,4}$ However in the last decades there has been a significant increase of ectopic pregnancy and a subsequent increase of heterotopic pregnancy. This raised frequency has been attributed to several factors including higher incidence of pelvic inflammatory disease and the extended use of assisted reproductive technologies.

However, the spontaneous occurrence is extremely rare and the diagnosis and management require high index of suspicion and delicate handling for an improved obstetrical outcome of on-going viable intrauterine pregnancy. This is a case report eliciting similar occurrence of spontaneous heterotopic pregnancy and the subsequent obstetrical outcome of the patient.

\section{CASE REPORT}

23yr old primigravida was referred to our institute as a case of twin's pregnancy with one nonviable fetus with amenorrhea 4th month and pain abdomen for 2months with low back ache. She was married for 1year and this was a spontaneous conception with period of gestation 16w6d from her last menstrual period. Her outside ultrasound was showing uterus with two gestational sacs with one live fetus of average gestation of 12 weeks 4 days and other $\mathrm{G}$ sac showing heterogenous mass with gestation 13 weeks with no fetal cardiac activity.

Pt was relatively hemodynamically stable with pulse $86 / \mathrm{m}$, afebrile to touch and blood pressure $124 / 84 \mathrm{mmhg}$ in $\mathrm{rt}$ radial artery with mild pallor. On per abdomen examination abdomen was soft with slight tenderness in 
left iliac region. Uterus was enlarged to $16 \mathrm{wks}$ and was tense. Per speculum examination was insignificant. On per vaginum examination os was closed with cervical length $2.5 \mathrm{~cm}$ and uterus was anteverted 14- 16 weeks size with tenderness and fullness in left adnexa. Right adnexa clear.

Her emergency investigations were done and an ultrasound was done which showed one viable intrauterine pregnancy with right side dermiod cyst and another complex mass of size $12 \times 8 \mathrm{~cm}$ likely nonviable pregnancy in separate uterine horn with moderate free fluid in abdomen.

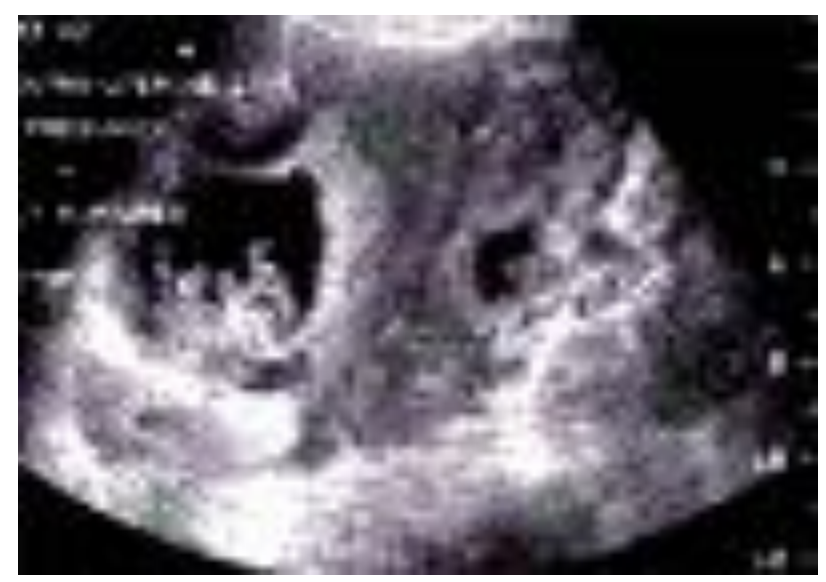

Figure 1: USG confirming heterotopic pregnancy.

Her haemoglobin was $7.7 \mathrm{~g} / \mathrm{dl}$. Decision for exploratory laparotomy was made in view of suspected ruptured ectopic pregnancy.

Intraoperatively, there was hemoperitoneum of $500 \mathrm{cc}$. Uterus enlarged to 12-14 weeks size. Posterior surface of uterus adherent to left tubo- ovarian mass of 12 X $10 \mathrm{~cm}$. and sigmoid colon'Left tube and ovary could not be distinguished and was ballooned up containing hemorrhagic material (clots approx. 1 litres). Left salpingo-oophorectomy done and tubo-ovarian mass containing clots and fetal tissue was sent for histopathological examination.

One unit of whole blood was transfused post-operatively. Her post-operative period was uneventful and she was discharged after suture removal on 5th day. Histopathological examination showed fallopian tube fragment showing features of decidualisation, confirming ectopic gestation.

She was followed up till term and had full term normal vaginal delivery of a healthy female baby of $2.75 \mathrm{~kg}$.

\section{DISCUSSION}

Heterotopic gestation, although fairly common with assisted reproductive techniques, is very rare in natural conception. ${ }^{5}$ It occurs in 1 in 30, 000 of spontaneous pregnancies, 1 in 900 in clomiphene citrate induced pregnancies, and rises to $1 \%$ in assisted reproduction. ${ }^{6}$ Risk factors for ectopic pregnancy are pelvic inflammatory disease (PID), tubo-ovarian abscess (TOA), previous ectopic pregnancies, previous tubal surgery etc.

Its diagnosis requires high index of suspicion and is often delayed. The presence of an intrauterine pregnancy, either viable or not, may actually mask the ectopic component of a heterotopic pregnancy, resulting in delay of diagnosis. The early diagnosis of heterotopic pregnancy is difficult; $\beta$-hCG alone is not helpful to diagnosis heterotopic pregnancy. The intrauterine pregnancy masks any underlying $\beta$-hCG changes from the extra-uterine pregnancy and vice versa. Often the diagnosis is made during operation or after the histopathological report.

In the present case, the intrauterine pregnancy and extrauterine pregnancy were discovered simultaneously via ultrasound. Surgical management was done to remove the extrauterine nonviable product of conception which allowed the viable intrauterine pregnancy to develop to term, ultimately leading to a spontaneous vaginal delivery. Thus all surgeons operating for ruptured ectopic must bear possibility of heterotopic pregnancy in mind and must handle uterus with care. ${ }^{7}$ Treatment should be as minimally invasive as possible to preserve the developing intrauterine pregnancy. 8 With early diagnosis and treatment, $70 \%$ of the intrauterine pregnancies will reach viability. ${ }^{9}$ All operated patients with ruptured ectopic must be followed up with clinical examination, and subsequent ultrasonography and $\beta$ hCG levels on clinical suspicion of on-going intrauterine pregnancy.

\section{CONCLUSION}

In the case of ectopic pregnancy undergoing surgical management, intrauterine device such as uterine manipulator should be generally avoided due to the likelihood of coexistence of early intrauterine pregnancy that is not visualized by ultrasound. In the case of confirmed intrauterine pregnancy with abdominal pain, further workup and close monitoring should be considered to rule out heterotopic pregnancy especially after ART techniques.

\section{Funding: No funding sources \\ Conflict of interest: None declared \\ Ethical approval: Not required}

\section{REFERENCES}

1. $\mathrm{Mj} \mathrm{G}, \mathrm{RR}$. Heterotopic pregnancy in natural conception. J Hum Reprod Sci. 2008;1:37-8.

2. Hassani KI, Bouazzaoui AE, Khatouf M, Mazaz K. Heterotopic pregnancy: a diagnosis we should suspect more often. J Emerg Trauma Shock. 2010;3:304.

3. Reece EA, Petrie RH, Sirmans MF, Finster M, Todd WD. Combined intrauterine and extrauterine 
gestations: a review. Am J Obstet Gynecol. 1983;146:323-30.

4. Devoe RW, Pratt JH. Simultaneous intrauterine and extrauterine pregnancy. Am J Obstet Gynecol. 1948;56:1119-26.

5. Engdayehu D, Bekuretsion Y. Heterotopic pregnancy in a young adult: a case report. Ethiop Med J. 2012;50(3):265-70.

6. Tal J, Haddad S, Gordon N, Timor-Tritsch I. Heterotopic pregnancy after ovulation induction and assisted reproductive technologies: a literature review from 1971 to 1993. Fertil Steril. 1996;66(1):1-12.

7. Fouedjio JH, Fouelifack FY, Fouogue JT, Sando Z. Ruptured heterotopic pregnancy in a natural conception cycle: a case report at the Yaounde central Hospital (Cameroon). Pan Afr Med J. 2013;16:106.

8. Louis-Sylvestre C, Morice P, Chapron C, Dubuisson JB. The role of laparoscopy in the diagnosis and management of heterotopic pregnancies. Hum Reprod. 1997;12:1100-2.

9. Nguyen-Tran C, Toy EC. Heterotopic pregnancy: viable twin intrauterine pregnancy with a viable right tubal ectopic pregnancy. J Ultrasound Med. 2000;19(5):355.

Cite this article as: Gupta A, Gupta A, Gupta B, Mahajan N, Vij A, Chadha A. Heterotopic pregnancy: a case report. Int J Reprod Contracept Obstet Gynecol 2017;6:2121-3. 